\title{
ANALISIS PENDAPATAN USAHA TANI STOBERI DI TEMPAT WISATA D'MOOAT DESA MOAT KECAMATAN MODAYAG KABUPATEN BOLAANG MONGONDOW TIMUR
}

\author{
Shierly Angelina Stephanie Suprianto \\ Agnes Estephina Loho \\ Benny Adrian Berthy Sagay
}

\begin{tabular}{ll}
\hline Naskah diterima melalui Website Jurnal Ilmiah agrisosioekonomi@ unsrat.ac.id & : Kamis, 30 Januari 2020 \\
Disetujui diterbitkan & : Jumat, 29 Mei 2020 \\
\hline
\end{tabular}

\begin{abstract}
This study aims to determine the income of strawberry farming in the tourist attractions of $D$ 'Mooat and also want to know the value of $R / C$ ratio. The data used are primary data and secondary data. This research was conducted in November 2018 until January 2019. The research method used was a case study by taking Mooat Village, which is the only village that cultivates strawberry plants in East Bolaang Mongondow Regency. Analysis of the data used is farm analysis and $R / C$ analysis. The results of the research showed that the receipt of strawberries in one year at the tourist site D'Mooat of 8000 polybags was $R p$. 162,000,000 with an expenditure of $R p$. 57,721,500 so that it gives an income of $R p$ 104,278,500 or Rp 8,689,875 / month with an R / C value> 2,47. Strawberry farm income is profitable because it is 2.85 times greater than the minimum monthly wage in North Sulawesi Province. ${ }^{* e p r m *}$
\end{abstract}

Keywords: strawberry farming, farm analysis, strawberry farm income, tourist attraction D'Mooat

\begin{abstract}
ABSTRAK
Penelitian ini bertujuan untuk mengetahui pendapatan usahatani stroberi di tempat wisata D'Mooat dan juga ingin mengetahui nilai $\mathrm{R} / \mathrm{C}$ ratio. Data yang digunakan adalah data primer dan data sekunder. Penelitian ini dilakukan pada bulan November 2018 hingga Januari 2019. Metode penelitian yang digunakan adalah studi kasus dengan mengambil Desa Mooat yang merupakan satu-satunya Desa yang mengusahakan tanaman stroberi di Kabupaten Bolaang Mongondow Timur. Analisis data yang digunakan adalah analisis usahatani dan analisis R/C. Hasil penelitian penelitian menunjukkan bahwa penerimaan stroberi dalam satu tahun di lokasi wisata D'Mooat dari 8000 polibag sebesar Rp. 162,000,000 dengan pengeluaran sebesar Rp. 57.721 .500 sehingga memberikan pendapatan sebesar Rp 104.278.500 atau Rp 8.689.875/bulan dengan nilai R/C > 2,47. Pendapatan usahatani stroberi menguntungkan karena 2,85 kali lebih besar dibandingkan dengan upah minimum per bulan di Provinsi Sulawesi Utara.
\end{abstract}

Kata kunci: usahatani stroberi, analisis usahatani, pendapatan usahatani stroberi, tempat wisata D’Mooat. ${ }^{*}$ eprm*

Agrisosioekonomi:

Jurnal Transdisiplin Pertanian (Budidaya Tanaman, Perkebunan, Kehutanan, Peternakan, Perikanan), Sosial dan Ekonomi 


\section{PENDAHULUAN}

\section{Latar Belakang}

Stroberi merupakan salah satu komodili buah asli daerah beriklim sub tropis yang berasal dari chili. Sejarah holtikultura mencatat bahwa stroberi pada abad 14 pernah diusahakan dalam bentuk "Perkebunan" di Perancis, sedang di Eropa stroberi mulai dibudidayakan mulai abad 17-18 (Gunawan,1996). Tanaman stroberi di Indonesia dapat ditanam sepanjang tahun tanpa terganggu oleh adanya pergantian musim setiap tahunnya sepertinya yang terjadi di negaranegara yang mempunyai empat musim yaitu: Belanda, Amerika, dan Australia (Soemadi, 1997). Buah stroberi merupakan buah yang mempunyai nilai ekonmi yang tinggi dengan berbagai manfaat seperti dan merupakan sumber vitamin dan mineral untuk memenuhi kebutuhan gizi manusia (Soemadi, 1997). Hasil penelitian Setyowati (2011) menunjukkan bahwa R/C ratio usahatani storberi Di Desa Kalisoro Kecamatan Tawangmanggu sebesar 1,57 sedangkan hasil penelitian Wuner (2015) menujukkan bahwa R/C usahatani stroberi di Kelurahan Rurukan sebesar 5,4 dengan pendapatan sebesar Rp 21.437.043/1000 tanaman selama delapan bulan. Selanjutnya Loho dkk (2018) menunjukkan bahwa pandapatan pendapatan usahatani stroberi di tempat wisata D'Mooat sebesar Rp 16.063.156/bulan.

Stroberi membutuhkan persyaratan tumbuh dengan ketinggian $1000-1500 \mathrm{~m}$ dari permukaan laut dengan temperatur $17-200{ }^{\circ} \mathrm{C}$ dan kelembaban $80-90 \%$. Meskipun demikian petani di Sulawesi utara pada daerah tertentu dengan agroekologi yang cocok masih sangat jarang untuk membudidayakan tanaman ini. Menurut Loho dkk, (2018) salah satu penyebab kurangnya minat petani untuk membudidayakan stroberi di Kelurahan Rurukan Kota Tomohon adalah tingginya intensistas aktivitas dalam usahatani ini, dan adanya cuaca esktrim. Pembudidayaan tanaman ini membutuhkan pengalokaian sumber daya secara yang efektif dan efisien. Pengalokasian sumberdaya yang efisien akan memberikan pendapatan yang maksimum. Oleh sebab itu sektor pertanian perlu mendapat perhatian karena umumnya penduduk Indonesia hidup dan dihidupkan dari usaha pertanian (Soekartawi, 2002).
Kabupaten Bolaang Mongondow Timur merupakan daerah yang terletak antara 905$1500 \mathrm{M}$ dari permukaan laut dengan iklim yang cocok untuk tanaman hortikultura. Tempat wisata D'Mooat terletak $1100 \mathrm{M}$ dari permukaan laut. Salah satu komoditi yang mulai dikembangkan tempat wisata ini adalah tanaman stroberi dan menjadi perhatian khusus wisatawan. D'Mooat merupakan salah tempat wisata yang memiliki perkebunan stroberi. Berawal dari hobi pemilik untuk bercocok tanam kemudian mengembangkan usaha ini untuk dijadikan objek wisata stroberi dengan berbagai fasilitas berupa wahan bermain, lokasi swafoto dan kafe. Stroberi tidak hanya menjadi daya tarik di mata anak-anak namun juga memikat hati orang orang dewasa dengan berbagai manfaat. Untuk mengetahui pengembangan tanaman stroberi ini, maka perlu diketahui pendapatan usahatani stroberi.

\section{Rumusan Masalah}

Rumusan masalah dalam penelitian ini adalah berapa besar pendapatan usahatani dari stroberi di perkebunan D'Mooat dan berapa besar kontribusi biaya terhadap penerimaan?

\section{Tujuan Penelitian}

Tujuan penelitian adalah: Untuk menganalisis pendapatan usahatani dari stroberi di perkebunan D'Mooat dan mengetahui kontribusi biaya terhadap penerimaan.

\section{Manfaat Penelitian}

Penelitian ini diharapkan bermanfaat bagi pengembagan ilmu pengetahuan khususnya pengembangan usahatani stroberi dan dapat menjadi bahan masukan untuk peneliti selanjutnya untuk usahatani perkebunan stroberi.

\section{METODE PENELITIAN}

\section{Waktu dan Tempat Penelitian}

Penelitian ini dilakukan selama 3 bulan mulai dari November 2018 sampai Januari 2019 di tempat wisata D'Mooat yang berlokasi di Desa Moat Kecamatan Modayag Kabupaten Bolaang Mongondow Timur. 


\section{Metode pengumpulan data}

Data yang digunakan dalam penelitian ini adalah data primer dan sekunder. Data primer diperoleh dengan cara mewawancarai langsung pemilik Perkebunan stroberi D'Mooat serta tenaga kerja berdasarkan daftar pertanyaan (kuesioner) yang telah disusun dan observasi langsung di tempat penelitian. Data sekunder diperoleh dari sumber lainnya seperti hasil penelitian, jurnal dan skripsi yang berhubungan dengan penelitian ini.

\section{Konsep Operasional dan Pengukuran Variabel}

1. Produksi yaitu jumlah produksi stroberi dalam setahun (kg/tahun).

2. Biaya Variabel yang terdiri dari biaya bibit, pupuk, pengendalian hama dan penyakit, dan tenaga kerja ( $\mathrm{Rp} /$ tahun).

3. Biaya tetap yang terdiri dari pajak, tatakan tanaman stroberi, peralatan yang digunakan dalam usahatani (Rp/tahun).

4. Harga bibit, pupuk, pestisida, dan upah tenaga kerja (Rp/unit).

5. Harga stoberi $(\mathrm{Rp} / \mathrm{kg})$.

\section{Metode Analisis Data}

Analisis yang dilakukan dalam hipotesis ini adalah sebagai berikut:

1. Untuk mengetahui besarnya pendapatan digunakan analisis pendapatan dengan rumus:

$$
\mathrm{Pd}=\mathrm{TR}-\mathrm{TC}
$$

\section{Keterangan:}

$\operatorname{Pd}($ pendapatan $)=$ pendapatan bersih usaha tani

$\mathrm{TR}($ total revenue $)=$ total penerimaan

$\mathrm{TC}($ total cost $) \quad=$ total biaya

Total Penerimaan (TR) diperoleh dari:

$$
\mathrm{TR}=\text { Py. } \mathrm{Y}
$$

Py adalah harga produk

$\mathrm{Y}$ adalah jumlah produk

Total Biaya (TC) diperoleh dari

$\mathrm{TC}=\mathrm{FC}+\mathrm{VC}$

FC adalah biaya tetap VC adalah biaya tidak tetap (biaya variable)
2. Untuk megetahui kontribusi biaya terhadap penerimaan digunakan analisis $\mathrm{R} / \mathrm{C}$ dengan rumus:

$$
\begin{aligned}
& \mathrm{R} / \mathrm{C}=(\mathrm{Py} . \mathrm{Y}) /(\mathrm{FC}+\mathrm{VC}) \\
& =\mathrm{TR} / \mathrm{TC}
\end{aligned}
$$

Keterangan:

Ada 3 kriteria dalam perhitungan ini, yaitu:

1. Jika $\mathrm{R} / \mathrm{C}<1$, maka usahatani yang dilakukan secara ekonomis belum menguntungkan.

2. Jika $\mathrm{R} / \mathrm{C}=1$, maka usahatani berada pada titik impas (Break Event Point), tidak untung dan tidak rugi.

3. Jika $\mathrm{R} / \mathrm{C}>1$, maka usahatani yang dilakukan secara ekonomis menguntungkan.

\section{HASIL DAN PEMBAHASAN}

\section{Deskripsi Umum Wisata D'Mooat}

Tempat Wisata D'Mooat adalah tempat wisata yang terletak Desa Moat Kecamatan Moat Kabupaten Bolaang Mongondow Timur dengan luas wilayah desa $13.21 \mathrm{~km} 2$. Batas - batas wilayah desa moat adalah sebagai berikut:

\section{Sebelah Utara : Gunung Ambang}

Sebelah Timur : Desa Bongkudai Selatan

Sebelah selatan : Desa Purworejo

Sebelah Barat : Desa Atoga

Tempat Wisata D'Mooat merupakan satu-satunya tempat wisata di desa Moat dengan komoditi unggulan tanaman stroberi. Stroberi merupakan buah yang belum dibudidayakan di Kabupaten Bolaang Mongondow Timur sehingga menjadi daya tarik tersendiri bagi pengunjung tempat Wisata D'Mooat. Tempat wisata ini ini mulai dirintis sejak Juli 2017 oleh saudara Cynthia Loho, SP. Beliau berumur 39 tahun dan merupakan lulusan sarjana pertanian Universitas Sam Ratulangi Manado. Pengelolaannya menggunakan manajemen keluarga. Sdri Chyntia mengelola Café dan wahana bermain anak, sedangkan Ibunya mengelola kebun stroberi dan kebun bunga serta tempat swafoto.

Dalam proses usaha ini, selain stroberi sebagai tanaman yang menarik, juga merupakan salah satu bahan baku untuk cafe yang berada di tempat isata menjadi berbagai macam juice stroberi dan penganan ringan. 
Tempat Wisata D'Mooat mulai beroperasi dari pagi pukul 10:00 hingga 17:00 WITA pada hari senin-jumat sedangkan pada hari sabtu-minggu dibuka pada pulul 09:00 WITA hingga 18-00 WITA. Bangunan yang dipakai untuk usaha merupakan milik sendiri dari pemilik usaha.

\section{Usahatani Stroberi di Tempat Wisata D'Mooat}

\section{Pembibitan}

Pada umumnya jenis bibit stroberi yang dibididayakan adalah jenis Strawberry California berukuran sedang dengan rasa manis asam dan berwarna merah. Bibit yang di tanam di Tempat Wisata D'Mooat berasal dari tanaman induk yang berumur 1-2 tahun yang sehat dan produktif yang telah dipilih dari rumpun yang telah memiliki akar sulur pertama dan kedua kemudian akar sulur dipotong lalu bibit di tanam di dalam polibag $18 \times 15 \mathrm{~cm}$ yang telah diisi campuran tanah, pupuk kandang, sekam padi dan kulit kopi. Setelah tinggi tanaman mencapai $10 \mathrm{~cm}$ dan berdaun rimbun maka bibit siap untuk dipindahkan ke polybag yang telah disiapkan.

\section{Media Tanam}

Media tanam di Tempat Wisata D'Mooat menggunakan media tanam polibag dan diatur diatas tatakan. Tatakan berguna agar tanaman stroberi lebih tinggi dari permukaan tanah dan sulur stroberi nantinya akan menggantung sehingga tidak akan menyentuh tanah. Pembuatan media tanam campuran dari tanah yang gembur, kompos atau pupuk kandang, kulit kopi dan sekam padi dengan perbandingan yang sama. Semua bahan-bahan ini dicampur hingga rata. Setelah semua bahan telah tercampur, ditutup dengan menggunakan terpal atau sejenisnya kemudian didiamkan selama 1 hari untuk kemudian dimasukkan ke dalam polibag yang akan ditanami stroberi.

\section{Penanaman}

Polibag yang sudah disiapkan diisi dengan tanah kemudian masukan bibit tanaman yang sudah disiapkan terlebih dahulu. Untuk menopang agar bibit tegak dalam polybag digunakan kayu kecil yang sudah disesuaikan dengan tinggi tanaman.

\section{Pemeliharaan \\ a. Penyulaman}

penyulaman dilakukan sebelum tanaman berumur 15 hari setelah tanam. tanaman yang disulam adalah yang mati atau tumbuh abnormal.

\section{b. Penyiangan}

Penyiangan dilakukan secara teratur untuk memastikan tidak ada tanaman lain yang tumbuh di dalam polybag dengan mencabut rumput atau gulma yang tumbuh dalam polibag.

\section{c. Pemangkasan}

Tanaman yang terlalu rimbun/terlalu banyak daun harus dipangkas. Pemangkasan juga dilakukan teratur terutama untuk membuang daun-daun tua/rusak.

\section{d. Pemupukan}

Pupuk NPK dengan kandungan Nitrogen yang tinggi pada saat pertumbuhan sebanyak 1 sdm, sedangkan pada saat pembungaan pupuk NPK dengan kandungan Posphoe dan Kalium yang tinggi sebanyak 1 sdm. Pemupukan dilakukan setiap seminggu sekali dengan takaran $1 \mathrm{sdm}$ untuk satu polibag ukuran besar. Pupuk organik juga digunakan seperti hatake

\section{e. Penyiraman}

Penyiraman dilakukan 2 kali sehari jika tidak turun hujan setelah itu penyiraman dikurangi perlahan dengan syarat tanah tidak boleh kering. Sumber air yang dipakai di perkebunan ini langsung dari air sumur.

\section{Hama dan penyakit}

Hama yang biasa menganggu tanaman stroberi di Tempat Wisata D'Mooat yaitu tikus yang menyerang buah, belalang dan ulat yang menyerang daun, dan water tanah (semacam cacing berwarna merah) yang terdapat di media tanam. Cara penanganan pada hama tersebut yaitu untuk tikus digunakan temik, belalang digunakan besvidor, sedangkan untuk ulat digunakan antracol dan sevin. 
Penyakit yang biasa mengganggu tanaman stroberi di Tempat Wisata D'Mooat adalah busuk akar. Cara yang di gunakan petani di tempat Wisata D'Mooat untuk mengatasi hama dan penyakit yaitu dengan daun pepaya yang telah ditumbuk lalu di campur tembakau kemudian rendam selama 1 malam dan campurkan obat toxiput dan di percikpercikkan di daerah yang terkena hama maupun penyakit.

\section{Panen}

Tanaman stroberi dapat di panen setelah berumur 4 bulan dari masa bibit dan akan terus berbuah sampai kurang lebih 2 tahun. Namun pada umur 1 tahun kualitas buah mulai mengalami penurunan. Pemanenan sebaiknya dilakukan pada pagi hari sebelum buah terpengaruh udara panas. Jika terlalu siang suhu udara yang panas membuat metabolism buah cepat sehingga mengurangi waktu simpan buah. Pemanenan di Tempat Wisata D'Mooat dilakukan setiap 3 hari dalam seminggu. Stroberi yang di petik adalah buah yang sudah agak kenyal dan berwarna merah kekuning-kuningan. Buah yang dipanen dikumpulkan dalam 1 keranjang kecil dan dikumpulkan dalam 1 wadah, tidak boleh ada buah stroberi yang rusak agar tidak membuat buah yang lain rusak. Buah yang telah dipanen disimpan di tempat yang telah disediakan.

\section{Pasca Panen}

Buah yang telah dipanen diolah di tempat Wisata D'Mooat menjadi aneka minuman dan makanan seperti jus, milkshake, dan salad. Ada juga yang dijual dalam bentuk buah stroberi segar yang telah dikemas dalam wadah berbentuk mika.

\section{Pemasaran}

Pemasaran buah stroberi hanya di temapt wisata itu sendiri dengan dijadikan olahan makanan dan minuman dan dalam bentuk buah segar. Untuk pemasaran keluar sendiri belum dilakukan karena baru memenuhi kebutuhan café dan permintaan pengunjung.

\section{Analisis Usahatani Stroberi}

Analisis pendapatan petani dilakukan untuk menemukan berapa pendapatan petani yang diperoleh dari usahatani stroberi. Dalam analisis pendapatan menjelaskan tentang bagaimana struktur biaya, pendapatan dan rasio $\mathrm{R} / \mathrm{C}$ dari usahatani stroberi.

\section{Biaya Usahatani}

Produksi merupakan serangkaian kegiatan yang dilewati petani dalam menghasilkan suatu produk. Dalam melakukan proses produksi diperlukan biaya sebagai penunjang kegiatan ini. Terdapat dua jenis biaya yaitu biaya Tetap dan biaya Variabel.

1. Biaya Tetap

Biaya tetap merupakan biaya untuk pembelian alat dan sarana prasaran untuk kegiatan budidaya stroberi meliputi tatakan polybag, sprayer, cangkul, parang, gunting stek dan pajak yang dijabarkan dalam Tabel 1 di bawah ini:

Tabel 1. Biaya Tetap Usahatani Stroberi

\begin{tabular}{lcrr}
\hline $\begin{array}{l}\text { Komponen } \\
\text { Biaya }\end{array}$ & $\begin{array}{c}\text { Jumlah } \\
\text { (unit/tahun) }\end{array}$ & $\begin{array}{c}\text { Nilai } \\
\text { Penyusutan } \\
\text { (Rp) }\end{array}$ & $\begin{array}{l}\text { Total } \\
\text { Biaya }\end{array}$ \\
\hline PBB & 1 & 100.000 & 100.000 \\
Tatakan & 39 & 60.000 & 2.340 .000 \\
Sprayer & 2 & 137.500 & 275.000 \\
Cangkul & 2 & 37.500 & 75.000 \\
Parang & 2 & 37.500 & 75.000 \\
Gunting stek & 2 & 62.500 & 125.000 \\
\hline & & Total Biaya Tetap & $\mathbf{2 . 9 9 0 . 0 0 0}$
\end{tabular}

Tabel 1 menunjukkan bahwa biya terbesar adalah tatakan stroberi. Hal ini disebabkan karena tatakan di tempat penelitian terbuat dari baja ringan. Hal ini untuk menjaga kekuatan topangan polybag yang ditanami storberi juga memberikan kerapihan dan keindahan.

2. Biaya Variabel

Biaya variable yang terjadi di lokasi penelitian meliputi biaya persiapan, biaya pupuk, biaya pestisida dan biaya tenaga kerja.

a. Biaya Persiapan Tanam

Persiapan tanam yang dilakukan petani mulai dari penyiapan polybag, media tanam berupa campuran tanah, pupuk kandang, kulit kopi dan sekam padi. Bibit adalah bibit yang ditanam di polybag kecil yang akan dipindahkan di polybag besar. Rincinan penggunaan dan biayanya disajikan pada Tabel 2 di bawah ini:

\begin{tabular}{|c|c|c|c|}
\hline Komponen Biaya & $\begin{array}{c}\text { Jumlah } \\
\text { (unit) }\end{array}$ & $\begin{array}{c}\text { Biaya } \\
\text { Satuan } \\
(\mathbf{R p})\end{array}$ & $\begin{array}{l}\text { Total } \\
\text { Biaya }\end{array}$ \\
\hline Polibag & 8.000 & 750 & 6.000 .000 \\
\hline Media Tanam & 8.000 & 1.076 & 8.608 .000 \\
\hline Bibit & 8.000 & 2.000 & 16.000 .000 \\
\hline
\end{tabular}


Biaya bibit merupakan biaya tertinggi untuk persiapan budidaya stroberi. Hal ini disebabkan karena biaya yang tejadi terdiri dari biaya media tanam, plastic, dan tenaga kerja. b. Biaya Pupuk

Pupuk yang digunakan adalah gabungan dari pupuk organik dan pupuk kimia. Hal ini dilakukan oleh pemilik karena belum yakin akan pengaruh pupuk organic. Pemupukan dilakukan secara intensif untuk menjaga produksi agar tidak turun. Rincian penggunaan dan biaya pupuk disajikan.

\begin{tabular}{|c|c|c|c|}
\hline Jenis Pupuk & $\begin{array}{c}\text { Jumlah } \\
\text { (unit/tahun) }\end{array}$ & $\begin{array}{c}\text { Harga } \\
\text { Pupuk (Rp) }\end{array}$ & $\begin{array}{l}\text { Total } \\
\text { Biaya }\end{array}$ \\
\hline Hatake & 24 & 30.000 & 720.000 \\
\hline Amway & 8 & 400.000 & 3.200 .000 \\
\hline MKP & 24 & 45.000 & 1.080 .000 \\
\hline Urea & 180 & 2.000 & 360.000 \\
\hline NPK & 400 & 2.300 & 920.000 \\
\hline Boron & 24 & 29.000 & 696.000 \\
\hline KNO3 Merah & 25 & 22.500 & 562.500 \\
\hline KNO3 putih & 25 & 20.000 & 500.000 \\
\hline Perekat & 3 & 95.000 & 285.000 \\
\hline
\end{tabular}

Biaya pupuk terbesar adalah Amway. Hal ini disebabkan oleh harga pupuk yang mahal. Meskipun NPK merupakan pupuk yang paling banyak digunakan namun harganya jauh lebih murah.

c. Biaya Pestisida

Pestisida digunakan untuk menanggulangi hama dan penyakit. Penngunaan serta biayanya dapat dilihat pada Tabel 4.

Tabel 4. Penggunaan dan biaya pestisida pada Usahatani

\begin{tabular}{|c|c|c|c|}
\hline \multicolumn{2}{|c|}{ Stroberi } & \multirow[b]{2}{*}{$\begin{array}{c}\text { Harga } \\
\text { Pestisida (Rp) } \\
\end{array}$} & \multirow[b]{2}{*}{$\begin{array}{l}\text { Total } \\
\text { Biaya } \\
\end{array}$} \\
\hline Jenis Pestisida & $\begin{array}{c}\text { Jumlah } \\
\text { (unit/tahun) }\end{array}$ & & \\
\hline Toxiput & 3 & 120.000 & 360.000 \\
\hline Antracol & 10 & 150.000 & 1.500 .000 \\
\hline Besvidor & 10 & 250.000 & 2.5000 .000 \\
\hline Tenik & 15 & 5.000 & 75.000 \\
\hline Sevin & 10 & 32.500 & 325.000 \\
\hline
\end{tabular}

Biaya pestisida terbesar adalah biaya pembelian besvidor karena harganya yang paling mahal dibandingkan dengan pestisida lainnya. d. Biaya Tenaga Kerja
Tenaga kerja yang digunakan dalam usahatani stroberi disajikan pada Tabel 5 di bawah ini:

Tabel 5. Curahan Tenaga Kerja dan Biaya Tenega Kerja

\begin{tabular}{|c|c|c|c|}
\hline Jenis Pekerjaan & $\begin{array}{c}\text { Jumlah } \\
\text { (unit/tahun) }\end{array}$ & $\begin{array}{c}\text { Upah } \\
\text { tenaga } \\
\text { kerja } \\
(\text { Rp) }\end{array}$ & $\begin{array}{l}\text { Total } \\
\text { Biaya }\end{array}$ \\
\hline Campur Tanah & 6 & 120.000 & 720.000 \\
\hline Isi Polibag & 8 & 120.000 & 960.000 \\
\hline Tanam & 6 & 120.000 & 720.000 \\
\hline Pemupukan & 24 & 120.000 & $2.880 . .000$ \\
\hline $\begin{array}{l}\text { Pengendalian } \\
\text { Hama dan penyakit }\end{array}$ & 12 & 120.000 & 1.440 .000 \\
\hline Penyiangan & 12 & 120.000 & 1.440 .000 \\
\hline Panen & 24 & 120.000 & 2.880 .000 \\
\hline
\end{tabular}

Biaya tenaga kerja yang terbesar adalah tenaga kerja pemupukan dan panen. Hal ini terjadi karena intensifnya pemupukan. Demikian juga dengan panen, karena setiap hari panen. Rekapitulasi dari biaya di atas dituangkan dalam Tabel 6.

Tabel 6. Rekapitulasi Biaya Usahatani Stroberi dalam setahun

\begin{tabular}{lrr}
\hline Komponen Biaya & \multicolumn{2}{c}{ Total Biaya } \\
\hline Biaya variabel & & \\
& Media tanam & 30.608 .000 \\
Pupuk & 8.323 .500 \\
Pestisida & 4.760 .000 \\
Biaya tetap & Tenaga kerja & 11.040 .000 \\
& Total biaya variable (TVC) & 54.731 .500 \\
& Alat & 2.890 .000 \\
& PBB & 100.000 \\
\hline Biaya Total & Total Biaya Tetap (TFC) & $\mathbf{2 . 9 9 0 . 0 0 0}$ \\
\hline
\end{tabular}

Tabel 6 menunjukkan bahwa biaya media tanam merupakan biaya terbesar diikuti oleh biaya tenaga kerja.

\section{Analisis Penerimaan}

Produksi stroberi mulai dipanen pada waktu tanaman berumur 4 bulan. Panen buah stroberi berkisar 3 sampai $6 \mathrm{~kg}$ perhari sehingga jumlah buah stroberi dari masa awal hingga akhir tahun berjumlah $1080 \mathrm{~kg}$. Harga jual perkilo yaitu Rp.150.000. Untuk memperoleh penerimaan maka digunakana rumus:

$$
\begin{aligned}
\mathbf{T R} & =\mathbf{P y} . \mathbf{Y} \\
& =\operatorname{Rp} 150.000 \times 1080=\operatorname{Rp} 216.000 .000
\end{aligned}
$$


Harga yang terjadi adalah harga buah stroberi yang dijual segar. Besar penerimaan dari usahatani stroberi sebesar Rp 216.000.000/tahun.

\section{Analisis Pendapatan}

Pendapatan merupakan hasil akhir usahatani yang merupakan keuntungan dalam usahatani. Pendapatan yang diperoleh tergantungn dari penerimaan yang diterima petani. Semakin tinggi penerimaan semakin tinggi pendapatan dengan asumsi biaya yang terjadi adalah konstan. Besarnya pendapatan diperoleh dari rumusan:

$$
\begin{aligned}
\mathbf{P d} & =\mathbf{T R}-\mathbf{T C} \\
& =216.000 .000-(54.731 .500+2.990 .000) \\
& =104.278 .500
\end{aligned}
$$

Keterangan:

$$
\begin{aligned}
& \text { Pd = pendapatan usahatani } \\
& \text { TR = Penerimaaan } \\
& \text { TC = Total Biaya = Total Biaya Variable } \\
& \text { + Total Biaya Tetap (TVC + TFC) }
\end{aligned}
$$

Besarnya pendapatan selama masa produksi satu tahun sebesar Rp 104.278.500 atau jika dijadikan pendapatan tiap bulan sebesar Rp 8.689.875/bulan masih diatas Upah minimum Provinsi Sulawesi Utara tahun 2019 sebesar Rp 3.051.076 atau 2,85 lebih besar dari upah minimum Provinsi. Hal ini berarti pendapatan usahatani stroberi sangat menguntungkan.

\section{Analisis Return Cost Ratio (R/C)}

Analisis ini digunkan untuk mengetahui tingkat keberhasilan dalam usahatani yang menunjukkan besarnya pengembalian pengeluaran terhadap penerimaan. Nilai $\mathrm{R} / \mathrm{C}>1$ berarti usahatani menguntungkan, sebaliknya jika $\mathrm{R} / \mathrm{C}<1$ berati usahatani tersebut merugi.

$$
\begin{aligned}
\mathbf{R} / \mathbf{C} & =\mathbf{T R} / \mathbf{T C} \\
& =162.000 .000 / 57.721 .500 \\
& =2,47
\end{aligned}
$$

Besarnya nilai R/C sebesar 2,47 menunjukkan bahwa usahatani stroberi menguntungkan. Nilai mengindikasikan bahwa setiap satuan rupiah ( $R p$ 1) yang dikeluarkan petani akan memberikan penerimaan sebesar 2,47 (Rp 2,47). Hal ini sejalan dengan penelitian yang telah dilakukan oleh Setyowati (2011) yang menunjukkan bahwa R/C 1,57 sehingga dapat disimpulkan bahwa usahtani stroberi di Moat lebih tinggi dibandingkan dengan di Desa Kalisoro, Kabupaten Karanganyar.

\section{KESIMPULAN DAN SARAN}

\section{Kesimpulan}

Penerimaan stroberi di lokasi wisata D'Mooat pada 8000 polibag sebesar Rp. $162,000,000$ dengan pengeluaran $\mathrm{Rp}$. 57.721 .500 sehingga memberikan pendapatan sebesar Rp 104.278.500 dengan nilai $\mathrm{R} / \mathrm{C}>$ 2,47 dan 2,85 kali lebih menguntungkan dibandingkan dengan upah minimum Provinsi Sulawesi Utara.

\section{Saran}

Perlunya meningkatkan penggunaan pupuk dan pestisida organik sebagai usaha untuk memberikan buah yang sehat dan menjagakelestarian lingkungan.

\section{DAFTAR PUSTAKA}

Gunawan. 1996. Stroberi. Penebar Swadaya. Jakarta.

Loho, dkk. 2018. Evaluasi Agribisnis Stroberi Organik di Kabupaten Bolaang Mongondow Timur Provinsi Sulawesi Utara. Jurnal Agri-Sosioekonomi Vol. 14 Nomor 3 September 2018.

Setyowati R. D. Ayumi, 2011. Analisis Pendapatan dan Efisiensi Usahtani Stroberi (Fragaria Sp): Studi Kasus di Desa Kalisoro, Kecamatan Tawangmangu Kabupaten Karangnyar Thesis. Universitas Brawijaya.

Soekartawi. 2002. Prinsip Dasar Ekonomi Pertanian Teori dan Aplikasi. PT Raja Grafindo Persada. Jakarta.

Soemadi. 1997. Budidaya Stroberi Di Pot dan Di

Kebun, CV. Aneka. Solo. 
Wuner. 2015. Kajian Usahatani Stroberi di Kelurahan Rurukan Kecamatan Tomohon Timur Kota Tomohon. Skripsi Fakultas Pertanian Universitas Sam Ratulangi. Manado. 